\section{THE WATER-TREATMENT CASE RELATED BY DR. SILVESTER.}

\section{To the Editor of THE LANCET.}

SIR,-Circumstances have prevented my seeing The Lancet for the last few weeks, but I am told that on the 24th of December (page 485) you published the case of the Rev. Mr. Good, and headed it " $A$ case of poisoning," by Priessnitz, with water."**

The case was one not treated by Priessnitz, but by Dr. Schmitz, physician to the Hydropathic Institution at Marienberg, near Boppart, who is the son of a distinguished Prussian judge. Mr. Good came to Marienberg, in the neighbourhood of which place $I$ happened to be then residing, some time in August or the beginning of September last. He was then affected with diabetes, which had reduced him to an extreme degree of emaciation and debility. His appearance indicated so great an amount of suffering, and so near an approach of dissolution, that he was an object of compassion, repeatedly expressed to me by his fellow-patients. Every one considered his death inevitable.

To everybody's surprise, shortly after commencing the treatment, his symptoms began to subside and his appearance rapidly to improve. His amendment continued, steadily and progressively, until the time of his leaving the institution. When he came to Marienberg he was, in a great measure, confined to his room. A week or two after the application of the water-cure $I$ repeatedly saw him climbing the steep mountains bordering that part of the Rhine. His progress was such as I was not at all prepared to expect, and gave me a higher opinion than anything $I$ had previously witnessed of the efficacy and value of the hydropathic method.

At the latter end of October, when labouring under a severe critical eruption of furuncles, \&c., Mr. Good suddenly announced to Dr. Schmitz his intention of learing the establishment. So great was the doctor's conviction of the danger he incurred by that suicidal step, that he remarked, "Monsieur Good is mad to think of leaving in his present condition." Notwithstanding this caution, Mr. Good proceeded on a tour, first to Frankfort, and then to England. The remainder of his history has been already told by others, I presume correctly.

Now, permit me to ask in what respect this case differs from the case of a person who commits some imprudence, which he knows to be injurious, while under the active influence of mercury, and suffers the same fatal consequences of his folly? or from that of another, who does the same thing after extensive depletion? It appears to me that

* It was headed "The Water Poison." ED. $\mathbf{L}$. the consequences in any of these cases are to be attributed entirely to the patient's own imprudent and obstinate conduct, and that such cases are by no means to be justly described as cases of poisoning, or of murder, on the part of the physician under whose treatment the patient has been salivated, or subjected to the hydropathic crisis.

I may remark, in conclusion, that the crisis is not unfrequently produced to the same extent as in this case in the large esta. blishments in Germany, without any danger whatever, if the necessary precantions are observed (although patients in the critical condition are by no means fit to undertake journeys of pleasure in October); and that Dr. Schmitz was, throughout his manage. ment of this case, assisted by the advice, and encouraged by the concurrence, of a distinguished surgeon and physiological writer of London. I am, Sir, your obedient servant,

Jas. Freeman, M.D.

Sherborne House, Cheltenham, Jan. 30, 1843.

\section{PHYSIOLOGY OF MENSTHUATION.}

THE following extract from a recent English writer shows that the views of Raciborski quoted in our last number (page 644), have been anticipated in our own country :-

"The following may be considered as the true state of the case respecting menstruation :--Since the uterus itself is not an essen. tial organ of generation, but merely superadded (in many species of animals), and since the influence of the ovaria and testes over all the other processes and organs connected with generation, including the existence of the uterus and its development during gestation, has been demonstrated, there appears not the slightest reason for withdrawing the phenomena of menstruation from their agency. It is in the ovaria, then, that we have to look for the causes of this process. There is every reason to believe that Graafian vesicles are coming forward at intervals during the whole period in which the reproductive organs are active; that these vesicles burst in succession, and shed the contained ovula, whether sexual connection takes place or not; and that, from recent researches (Gendrin, Negri, Paterson, Lee), these changes in them take place at each menstrual nisus. If we remember that during the period of heat in the lower mammals, as the ewe and sow, and of spawning and egg-laying, in birds, fishes, reptiles, insects-indeed, in every class of oviparous animals, these ovula become developed, and are shed-whether they be fructified or not, recurring at the same time to previous statements, we cannot help coming to the concla+ sion that the period of menstruation is precisely analogous to the period of heat. That 